\title{
The occurrence of left ventricular hypertrophy in normotensive individuals in a community setting in North-East Trinidad
}

This article was published in the following Dove Press journal:

Vascular Health and Risk Management

28 June 2011

Number of times this article has been viewed

\author{
Romel Bacchus \\ Kristianna Singh \\ ljaz Ogeer \\ Kameel Mungrue \\ Department Paraclinical Sciences, \\ Public Health and Primary Care Unit, \\ Faculty of Medical Sciences, \\ University of the West Indies, \\ EWMSC, Mt Hope, Trinidad
}

Objective: The purpose of this study is to determine primarily the occurrence of left ventricular hypertrophy (LVH) in normotensive Trinidadians.

Design and methods: Enrolment into the study required participants to have normal blood pressure $(\leq 140 / 90)$ using the JNC 7 (The Seventh Report of the Joint National Committee on Prevention, Detection, Evaluation, and Treatment of High Blood Pressure) classification, free of type 2 diabetes, as well as no existing LVH. Upon entry into the study, participants were first screened for LVH using a standard 12-lead electrocardiogram (ECG), using the Sokolow-Lyon index and the Cornell index. ECHO was used to confirm or refute the diagnosis of LVH.

Results: A total of 209 patients met the criteria for entry into the study. Of these, $63.6 \%$ had LVH using Cornell criteria and $68.2 \%$ using LVH by Sokolow-Lyon criteria. Subsequently, ECHO confirmed the diagnosis in $2.9 \%$ using American Society of Echocardiography criteria and $1.5 \%$ using World Health Organization criteria. Thus the estimated prevalence of LVH in normotensive individuals was approximately $3 \%$.

Conclusion: The estimated prevalence of $\mathrm{LVH}$ in normotensive individuals appears to be relatively high if an ECG is the single investigation performed, which is common in our setting and may also be common in the developing world. However, using ECHO, the prevalence of LVH approaches a value similarly reported in the literature. Therefore, these findings raise two important issues: 1) the use of criteria such as the Cornell and Sokolow-Lyon voltage criteria established in the developed world from populations of vastly different ethnic backgrounds may not be widely applicable, and 2) all individuals suspected of having LVH should have an ECHO.

Keywords: hypertension, normotensive, echocardiography, Sokolow-Lyon

\section{Introduction}

Left ventricular hypertrophy (LVH) occurs when left ventricular mass (LVM) exceeds the normal range, and it is a substantial independent predictor of cardiovascular morbidity and mortality. ${ }^{1}$ LVH can be physiological, occurring in athletes or adaptive to systemic hypertension, or aortic valve stenosis. ${ }^{2-4}$ It may occur in infiltrative systemic disease such as amyloidosis or lysosomal storage disease (Aderson-Fabry disease) ${ }^{5}$ or as familial hypertrophic cardiomyopathy. In a small proportion of individuals, LVH may occur without hypertension or any other recognized underlying pathology. ${ }^{6,7} \mathrm{We}$ refer to this subset of $\mathrm{LVH}$ as LVH in normotensive individuals.

LVH is a silent epidemic in North America, affecting more than $16 \%$ of the US adult population, and it is noted to be a progressive disorder. ${ }^{8}$ It increases morbidity by increasing the risk of arrhythmias, ischemic heart disease, and myocardial infarction. ${ }^{9}$
Correspondence: Kameel Mungrue Faculty of Medical Sciences, Department of Public Health and Primary Care, EWMSC, Mt Hope, Trinidad Tel +868 645674 I

Email kmungrue@fms.uwi.tt 
In addition, LVH is independently associated with an increased risk of stroke, sudden cardiac death, and heart failure. ${ }^{2,3}$ Carluccio et al reported that in 111 patients with acute myocardial infarction, 45\% with LVH developed further cardiac complications compared with $6.9 \%$ without LVH. ${ }^{10}$ In 1995, Liao et al reported that patients with LVH and normal coronaries had a mortality of $16.1 \% .{ }^{11}$ However, among those with single vessel disease and no LVH, the mortality was $10.9 \% .{ }^{11} \mathrm{LVH}$ more than doubled the risk of a fatal event, and for every 100 deaths, LVH independently accounted for $37 .{ }^{11}$ The presence of LVH was associated with a mortality risk of $50 \%$ greater than coronary artery disease ${ }^{10}$ Scuteri et al in 2009 noted that increase in LVM is associated with noncardiac complications such as cognitive decline and dementia in the elderly independent of elevated blood pressure (BP). ${ }^{12}$

In Trinidad and Tobago, cardiovascular disease is the leading cause of death, with hypertension being a significant contributor. ${ }^{13}$ In 2001, hypertension alone, without any other comorbidity accounted for $4.2 \%$ of total all-cause mortality. ${ }^{13}$

Apart from hypertension, the Framingham Heart Study in 1990 identified age, body mass index, and both visceral and free fat mass, as factors contributing to LVH. ${ }^{14}$ The prevalence of LVH increases with age, affecting more than one-third of individuals over the age of $70 .{ }^{8}$ Patrick et al reported in 1995 that $27.4 \%$ of men and $9.7 \%$ of women in Tobago had LVH. He further showed that mean LVM increased progressively across 10 -year age groups between 25 and 64 years in both sexes. ${ }^{15}$ In 1994, de Simone and colleagues identified in a New York setting that $14 \%$ of obese normotensive subjects had LVM above the upper limit as compared with $4 \%$ with normal weight. ${ }^{16}$

Diabetes and ethnicity have also been found to be associated with LVH. In 1998, Sato et al reported an increase LVM in normotensive Type 1 diabetic patients. ${ }^{17}$ In 2003 , Taskiran et al showed that in normotensive type 1 diabetic patients with autonomic neuropathy, LVM index (LVMI) was higher than healthy subjects. ${ }^{18}$

As far back as 1986, Radice et al demonstrated that normotensive adolescents with a family history of hypertension had an LVM significantly greater than normotensive adolescents with normotensive parents. ${ }^{19}$ In 1990, Alli and colleagues further demonstrated that $12.2 \%$ of normotensive adolescents who had a parent with hypertension, developed LVH as compared with $2 \%$ whose parents were normotensive. ${ }^{20}$
The purpose of this study is to determine primarily the prevalence of LVH in normotensive Trinidadians as well as to measure the proportion of various predisposing factors to cardiovascular disease among healthy individuals in the community.

\section{Method}

We used a cross-sectional study design. Participants were recruited from four Primary Health Care Facilities in North-East Trinidad. Enrolment into the study required participants to have normal BP $(\leq 140 / 90)$ at the time of entry, using the JNC 7 (The Seventh Report of the Joint National Committee on Prevention, Detection, Evaluation, and Treatment of High Blood Pressure) guidelines ${ }^{21}$ and free from type 2 diabetes World Health Organization (WHO) criteria. In addition participants were required to have no previous history of a diagnosis of hypertension including hypertension in pregnancy, no current or previous history of being treated for hypertension, and age $>16$ years. Participants who satisfied these criteria were further screened to exclude existing hypertension defined as a systolic $\mathrm{BP} \geq 140 \mathrm{mmHg}$ and a diastolic $\mathrm{BP} \geq 90 \mathrm{mmHg}, \mathrm{JNC} 7$ classification. ${ }^{21}$ Participants were also screened for pre-existing LVH due to any underlying pathological conditions such as diabetes, aortic stenosis, or alcoholic cardiomyopathy, by enquire and clinical records. Thus, only normotensive nondiabetic patients with no prior medical evidence of LVH were entered into the study.

Data were collected by asking the participants to complete a self administered pretested structured questionnaire containing 19 items. Clinical data collected include measurement of BP at the time of entry into the study. BP was measured initially in the sitting position using a mercury column sphygmomanometer using a standard technique: on the left arm of each subject using a cuff of appropriate size at the level of the heart. The cuff pressure was inflated $30 \mathrm{mmHg}$ above the level of which the radial pulse disappeared and deflated slowly at a rate of $2 \mathrm{mmHg} / \mathrm{second}$ and the reading recorded to the nearest $2 \mathrm{mmHg}$. The first (appearance) and the fifth (disappearance) Korotkoff sounds were recorded as indicative of the systolic BP and the diastolic BP respectively. In cases where the two readings differed by over $10 \mathrm{mmHg}$, a third reading was made and the three readings averaged. ${ }^{22}$

In addition, height $(\mathrm{m})$ and weight $(\mathrm{kg})$ were measured from which body mass index (BMI) $\left(\mathrm{kg} \mathrm{m}^{-2}\right)$ was calculated. Participants were classified as either overweight (BMI $25.0-29.9 \mathrm{~kg} \mathrm{~m}^{-2}$ ) or obese ( $\geq 30 \mathrm{~kg} \mathrm{~m}^{-2}$ ) according to WHO criteria. $^{23}$ 
Participants were then screened for LVH using a standard 12-lead electrocardiogram (ECG). Recordings were made with subjects lying flat in the supine position. The ECG machine was calibrated and tested prior to recording the ECG as outlined by the machine manual. The ECG coding quality assurance methods as outlined by the MONICA study was adopted for use in the study. ${ }^{24}$ As such, each ECG was coded by two independent coders, each unaware of the results of the other. Further, the codes established by the two coders separately were compared. However, if only one coder was available, the ECGs were subsequently re-coded after an interval of usually 24-48 hours. In the case of a discrepancy between the two coders, a third senior coder recoded the ECG without knowing the codes of the two other coders. After having established his/her own code, the three coders discussed the findings and made a final decision. ${ }^{24}$ We used both the Sokolow-Lyon index ${ }^{25}\left[\mathrm{~S}_{\text {in }} \mathrm{V}_{1}+\mathrm{R}\right.$ in $\mathrm{V}_{5}$ or $\mathrm{V}_{6}$ (whichever is larger) $\geq 35 \mathrm{~mm}$ ] and the Cornell index ${ }^{26}$ [R in AVL $+\mathrm{S}$ in V3, $>24 \mathrm{~mm}$ for males and $>20 \mathrm{~mm}$ for females], to establish LVH by ECG. Participants who had elevated $\mathrm{S}$ and $\mathrm{R}$ waves due to arrhythmias, ventricular ectopic beats, ventricular extrasystole, myocardial ischemia, acute myocardial infarction, left bundle branch block, acute pericarditis, hyperkalemia, pulmonary embolism, and digoxin toxicity were not considered as having pure LVH and were therefore eliminated from the analysis.

M-mode echocardiograms were recorded on strip-chart paper with the subject in a partial left decubitus position. M-mode recordings were made with the ultrasound beam at or just below the tips of the mitral valve leaflets. We used conventional LVM calculations based on linear measurements derived from two-dimensional targeted M-mode echocardiography. ${ }^{27}$ Strip-chart tracings were coded and interpreted by two blinded observers. Measurements of septal and posterior wall thickness and left ventricular chamber dimensions were obtained according to the guidelines of the American Society of Echocardiography (ASE). We used the ASE recommended formula ${ }^{28}$ for estimating LVM from left ventricle linear dimensions (validated with necropsy $r=0.90, P<0.001)^{27}$ which is based on modelling the left ventricle as a prolate ellipse of revolution. The formula used is $\mathrm{LVM}=0.8 \times(1.04$ [(LVIDd + PWTd + SWTd $)^{3}-\left(\right.$ LVIDd $\left.\left.^{3}\right]\right)+0.6$ g, where LVID is the left ventricular internal dimension, and PWTd and SWTd are posterior wall thickness at end diastole and septal wall thickness at end diastole, respectively. ${ }^{28}$ Calculation of relative wall thickness (RWT) by the formula $(2 \times$ PWTd)/LVIDd permits categorization of an increase in LVM as either concentric
(RWT $\geq 0.42$ ) or eccentric (RWT $\leq 0.42$ ) hypertrophy and allows identification of concentric remodelling (normal LVM with increased RWT). ${ }^{28}$

Using the recommendations of the ASE, ${ }^{26} \mathrm{LVH}$ was defined as (LVM/BSA) ${ }^{28}$ where BSA is body surface area calculated using the following formula: BSA $=((\operatorname{Height}(\mathrm{m})$ weight $(\mathrm{kg})) \times 3600)^{0.5}$. LVMI was measured by echocardiography normalized for body height to the allometric power of $2.7\left(\mathrm{LVMI}=\mathrm{LVM} /\right.$ height $\left.^{2.7}\right)$. LVH was defined as a LVMI $>50 \mathrm{~g} / \mathrm{m}^{2.7}$ for men and $>47 \mathrm{~g} / \mathrm{m}^{2.7}$ for women..$^{28,29,31}$ In addition, the LVM/BSA ratio was calculated as defined by the ASE, which is considered a more accurate way of normalizing LVM to the individual's BSA, with LVH defined as $>90 \mathrm{gm}^{-2}$ for women and $>114 \mathrm{gm}^{-3}$ for men. ${ }^{28}$

Due to constraints of availability and cost, echocardiography was restricted to approximately $64 \%$ of subjects who had LVH as defined by both the Sokolow-Lyon's and Cornell criteria.

Data were analyzed using SPSS version 16. Ethical approval for this study was obtained from The Ethics Committee of The University of The West Indies.

\section{Results}

A total of 224 patients were recruited for the study. In order to ensure that all patients who entered the study did not have hypertension BP was assessed at the time of entry into the study. Consequently, 15 patients met the criteria for hypertension for the first time (mean systolic BP $[\mathrm{MSBP}]=161 \pm 17$, mean diastolic BP $[\mathrm{MDBP}]=97 \pm 17 \mathrm{mmHg}$, and mean arterial pressures [MAP] ranging from 111 to $133.3 \mathrm{mmHg}$ ). In other words, while these patients gave no previous history of hypertension or were not receiving antihypertensive medications, BP at the time of entry into the study was elevated. Several factors may have contributed to this finding including white coat hypertension, unrecognized hypertension, or the use of drugs. In fact, four patients admitted to the use of cigarettes, five to the use of alcohol, three cocaine, and one the use of marijuana, a total of 14 of the 15 patients. In addition, seven reported a family history of high BP. Consequently, they were all eliminated from the analysis.

Of the 209 participants who were eligible for analysis, there were more females $(124,59.3 \%)$ than males $85(40.7 \%)$, and the mean age of females (36, SD \pm 13.8 years) was marginally higher than males ( $34, \mathrm{SD} \pm 13.5$ years), a detail of the characteristics of the sample are listed in Table 1. The proportion of LVH found based upon the four criteria used, two for ECG and two for echocardiogram are listed in Table 2. 
Table I Characteristics of study sample

\begin{tabular}{|c|c|c|c|c|}
\hline Sample characteristic & n (\%) & & Sample characteristic & n (\%) \\
\hline Gender & & & Smoking & \\
\hline Male & 85 (40.7\%) & & Current smoker & $19(9.1 \%)$ \\
\hline Female & $124(59.3 \%)$ & & Nonsmoker & $130(62.2 \%)$ \\
\hline \multirow[t]{2}{*}{ Total } & $209(100 \%)$ & & Previous smoker & $60(28.7 \%)$ \\
\hline & & & Total & $209(100 \%)$ \\
\hline Age range & Male & Female & Alcohol consumption & \\
\hline $17-26$ & $33(\mid 5.8 \%)$ & $40(19.1 \%)$ & Yes & $106(50.7 \%)$ \\
\hline $27-36$ & $15(7.8 \%)$ & 25 (II.9\%) & No & $103(49.3 \%)$ \\
\hline $37-46$ & $20(9.5 \%)$ & $31(14.8 \%)$ & Total & $209(100 \%)$ \\
\hline $47-56$ & II (5.2\%) & 17 (8.0\%) & Exercise & \\
\hline $57-66$ & $5(2.4 \%)$ & 7 (3.3\%) & Never & $58(27.8 \%)$ \\
\hline$>66$ & $\mathrm{I}(0.5 \%)$ & $4(1.9 \%)$ & $<3$ days/month & $39(18.7 \%)$ \\
\hline Total & $85(40.7 \%)$ & 124 (59.3\%) & Once per week & $34(16.3 \%)$ \\
\hline Ethnicity & & & $3 \times$ per week & $38(18.2 \%)$ \\
\hline SEA & $39(18.7 \%)$ & $50(23.9 \%)$ & $>3 \times$ per week & 40 (19.1\%) \\
\hline Africans & $37(17.7 \%)$ & $63(30.1 \%)$ & Total & $209(100 \%)$ \\
\hline Other & $09(4.3 \%)$ & II (5.3\%) & BMI & \\
\hline \multirow[t]{6}{*}{ Total } & $85(40.7 \%)$ & 124 (59.3\%) & $<18.5$ & $14(6.7 \%)$ \\
\hline & & & $18-24.9$ & $82(39.5 \%)$ \\
\hline & & & $25-29.9$ & 70 (33.3\%) \\
\hline & & & $30-35$ & $38(18.1 \%)$ \\
\hline & & & $>35$ & $5(2.4 \%)$ \\
\hline & & & Total & $209(100 \%)$ \\
\hline
\end{tabular}

Abbreviations: SEA, South East Asian; BMI, body mass index.

Using the Sokolow-Lyon criteria, 27 participants had LVH. However, 5 of the 27 participants had ST segment elevation in addition to LVH and were consequently eliminated from analysis. Hence, only $22(10.5 \%)$ patients had LVH using Sokolow-Lyon criteria (95\% confidence interval [CI], 10.1-10.9), with a higher proportion among males (17/85, $20.0 \%$ ) than females $(5 / 124,4.0 \%)$. The range of Sokolow-Lyon scores were $38.3-52.9 \mathrm{~mm}$, with a mean of $40.3(\mathrm{SD} \pm 4.7) \mathrm{mm}$. Using Pearson's correlation method, we attempted to correlate Sokolow-Lyon's scores with LVMI and found a correlation coefficient of $0.32(P=0.07)$, and with LVM/BSA, found a correlation coefficient of $0.37(P=0.045)$.

Similarly, using Cornell Voltage criteria, 11 (5.26\%), (95\% CI, 4.98-5.54) patients had LVH, again with a higher

Table 2 The proportion of LVH found using ECG and echocardiographic criteria

\begin{tabular}{llll}
\hline Criteria & Male & Female & Total \\
\hline ECG & & & \\
Sokolow-Lyon & $17(20.0 \%)$ & $5(4.0 \%)$ & $22(10.5 \%)$ \\
Cornel & $6(7.0 \%)$ & $5(4.0 \%)$ & $\mathrm{II}(5.3 \%)$ \\
Echocardiogram & & & \\
ASE & $3(20.0 \%)$ & $\mathrm{I}(6.7 \%)$ & $4(26.7 \%)$ \\
WHO & $\mathrm{I}(6.7 \%)$ & $\mathrm{I}(6.7 \%)$ & $2(13.3 \%)$ \\
\hline
\end{tabular}

Abbreviations: ASE, American Society of Echocardiography; ECG, electrocardiogram; LVH, left ventricular hypertrophy; WHO, World Health Organization. proportion in males $(6 / 85,7.0 \%)$ than females $(5 / 124,4.0 \%)$. The range for Cornell criteria for men was $29-40 \mathrm{~mm}$ with a mean of 32.5 ( $\mathrm{SD} \pm 4.03) \mathrm{mm}$, whereas for women was 21-42 mm with a mean of 26 (SD \pm 8.3 ). Using Pearson's correlation method, we attempted to correlate Cornell scores with LVMI and found a correlation coefficient of $0.53(P=0.047)$, and with LVM/BSA, found a correlation coefficient of 0.62 $(P=0.021)$.

Of the individuals who tested positive by the SokolowLyon criteria, 15/22 (68.2\%) were randomly chosen for confirmatory echocardiograms of whom 4/15 (26.7\%) tested positive for LVH using the ASE criteria and 2/15 (13.4\%) tested positive for LVH using the WHO criteria.

Extrapolating these results to all 22 subjects with LVH using ASE criteria, the estimated proportion of LVH in normotensive individuals is $2.9 \%$ (95\% CI, 2.77-3.23). However, using WHO guidelines the estimated proportion of confirmed LVH was $1.5 \%$ (95\% CI, 1.34-1.66).

Among individuals who tested positive using the Cornell voltage criteria, $7 / 11(63.6 \%)$ were randomly chosen for confirmatory echocardiograms, of whom 4/7 (57.1\%) tested positive for LVH using the ASE criteria and 2/7 (28.6\%) tested positive for $\mathrm{LVH}$ using the WHO criteria.

Extrapolating these results to all 11 subjects with LVH using ASE criteria, the estimated proportion of LVH in 
normotensive individuals is $2.9 \%$ (95\% CI, 2.77-3.23). However, using WHO guidelines, the estimated prevalence is $1.5 \%(95 \% \mathrm{CI}, 1.34-1.66)$.

\section{Discussion}

The main finding of this study was an estimated proportion of LVH in normotensive individuals of $2.9 \%$. Patrick and colleagues reported in 1995 a proportion of $27.4 \%$ in men and $9.7 \%$ in women using electrocardiographic (Sokolow-Lyon) criteria only. ${ }^{15}$ Our findings appear markedly lower, which may be attributed to more rigorous evaluation of $\mathrm{LVH}$, ie, the use of echocardiograms as well as the use of other criteria apart from the Sokolow-Lyon criteria. In addition, these values were reported among participants with both diabetes and hypertension. A review of the literature revealed two other studies of LVH in patients without hypertension or any pathological conditions associated with LVH: the first was reported by Antoniucci et al, in 1997, who reported a prevalence of $2.7 \%-3.2 \%$ adjusted for height, age, BMI, and BSA. ${ }^{6}$ The other in 2007, by Ruiz-Nodar et al who showed that in a group of elderly normotensive subjects with a mean age of 72 , the prevalence of LVH ranged from $30 \%$ by Cornell-Penn criteria to $14 \%$ by Devereaux criteria. ${ }^{31}$

Another important finding was although $60 \%$ of patients had increased LVM by echocardiographic evaluation when normalized for BSA according to ASE specifications and height according to WHO specifications, only four patients had LVH. Of these four participants, 20\% (3/15) were overweight as opposed to $6.7 \%(1 / 15)$ who had a normal weight. Similarly de Simone et al reported in 1994 that $14 \%$ of normotensive individuals who were overweight had LVH, compared with $5 \%$ who were normal weight. ${ }^{16}$ Our findings raise an issue for further investigation in normotensive patients: will reduction in BP below currently recommended targets reduce LVH.

The traditional Sokolow-Lyon voltage and the Minnesota code high QRS amplitude (WHO Monica study) are prone to errors by extra cardiac factors such as body weight, obesity, breast tissue, pulmonary conditions, chest size and shape in relation to cardiac size, QRS axis and ventricular conduction problems. Cornell voltage criterion is less vulnerable to such factors. ${ }^{33}$ In our setting based on a higher Pearson's correlation (Sokolow-Lyon $r=0.366$, Cornell $r=0.618$ ), we provide further support for this position. Sokolow and Lyon introduced their LVH criterion in $1949 .{ }^{32}$ Many studies have shown the sensitivity of this criterion is low, and it is perplexing that the Sokolow-Lyon's LVH criterion continues to be used in the clinical evaluation of patients, especially in the developing world with limited resources for more advanced evaluations. Rodrigues et al in 2008 showed the classic Sokolow-Lyon Rappaport and Cornell Voltage criteria showed a low performance in relation to $\mathrm{LVH}$, as confirmed by $\mathrm{ECHO},{ }^{33}$ our results support these findings as only 4 out of the 15 participants with LVH by Sokolow-Lyons criteria had confirmed LVH by echocardiography.

Alli and colleagues in 1990 showed that $12.2 \%$ of normotensive adolescents who had a parent with hypertension developed LVH. ${ }^{20}$ Our findings provide further evidence of a possible familial link between parental hypertension and the development of $\mathrm{LVH}$, as $100 \%$ of participants with echocardiographic confirmation of LVH gave a family history of high BP.

A major limitation of the study was the use of twodimensional echocardiography, which is less accurate and has greater test-retest variability than newer methods such as cardiac magnetic resonance imaging or real-time threedimensional echocardiography, which are unavailable on the island. The number of confirmed participants with LVH by echocardiographic was small hence risk factor analyses could not be conducted. In addition the availability and cost of echocardiograms restricted the number of participants who could be further assessed.

We recommend further studies with larger sample sizes with the capacity for all participants to be evaluated further using echocardiography. Risk factors associated with LVH should also be assessed. LVH in normotensive individuals is an important subset of cardiac patients, as Brown et $\mathrm{al}^{34}$ showed that individuals who were normotensive and had LVH had a greater risk of developing cardiac complications and as such should receive adequate follow up.

In conclusion, we provide evidence of the existence of LVH in normotensive individuals in Trinidad with a proportion of $2.9 \%$. LVH appears to be relatively high if an ECG is the single investigation performed, which is common in our setting and may also be common in the developing world. However using echocardiography, the prevalence of LVH approaches a similar value as reported in the literature. Therefore our study confirms: 1) the use of the Cornell and Sokolow-Lyon voltage criteria established in the developed world from populations of vastly different ethnic backgrounds may not be widely applicable, and 2) all individuals suspected of having LVH should have a confirmatory echocardiogram as part of their management.

\section{Disclosure}

The authors report no conflicts of interest in this work. 


\section{References}

1. Palmieri V, Wachtell K, Gerdts E, et al. Left ventricular function and hemodynamic features of inappropriate left ventricular hypertrophy in patients with systemic hypertension: the LIFE study. Am Heart J. 2001; 141(5):784-791.

2. Grant C, Greene DG, Bunnell IL. Left ventricular enlargement and hypertrophy. A clinical and angiocardiographic study. Am J Med. 1965; 39(6):895-904.

3. Moen MD, Wagstaff AJ. Losartan: a review of its use in stroke risk reduction in patients with hypertension and left ventricular hypertrophy. Drugs. 2005;65(18):2657-2674.

4. Carretero OA, Oparil S. Essential hypertension. Part I: definition and etiology. Circulation. 2000;101(3):329-335.

5. NaKao S, TaKenaKa T, Maeda M, et al. An atypical variant of Fabry's disease in men with left ventricular hypertrophy. $N$ Eng J Med. 1995; 333:288-293.

6. Antoniucci D, Seccareccia F, Menotti A, et al. Prevalence and correlates of echocardiographic determined left ventricular hypertrophy in 2318 asymptomatic middle-aged men: the ECCIS project. Epidemiolgia e Clinica della Cardiopatia Ischemica Silente. G Ital Cardiol. 1997; 27(4):363-369.

7. Martin T, Bhaskar Y, Umesh K. Clinical determinants of increased left ventricular mass on echocardiogram in medically treated Afro-Caribbean hypertensive patients. West Indian Med J. 2008;57:337-341.

8. Stansfield WE, Tang RH, Moss NC, Baldwin AS, Willis MS, Selzman CH. Proteasome inhibition promotes regression of left ventricular hypertrophy. Am J Physiol Heart Circ Physiol. 2008;294(2): H645-H650.

9. Mayo-Clinic, Staff. Left ventricular hypertrophy. Mayo Foundation for Medical Education and Research.; 2009 [cited 2009 06/11]. Available from: http://www.mayoclinic.com/health/left-ventricular-hypertrophy/ DS00680/DSECTION=complications. Accessed February 17, 2011.

10. Carluccio E, Tommasi S, Bentivoglio M, et al. Prognostic value of left ventricular hypertrophy and geometry in patients with a first, uncomplicated myocardial infarction. Int J Cardiol. 2000;74(2-3):177-183.

11. Liao Y, Cooper RS, McGee DL, Mensah GA, Ghali JK. The relative effects of left ventricular hypertrophy, coronary artery disease, and ventricular dysfunction on survival among black adults. JAMA. 1995; 273(20):1592-1597.

12. Scuteri A, Coluccia R, Castello L, Nevola E, Brancati AM, Volpe M. Left ventricular mass increase is associated with cognitive decline and dementia in the elderly independently of blood pressure. Eur Heart J. 2009;30(12):1525-1529.

13. PAHO. Health in Americas 2007. Washington D.C.: PAHO; 2007.

14. Savage DD, Levy D, Dannenberg AL, Garrison RJ, Castelli WP. Association of echocardiographic left ventricular mass with body size, blood pressure and physical activity (the Framingham Study). Am J Cardiol. 1990;65(5):371-376.

15. Patrick A, Boyd Patrick H, Henry R, Ince W, Holder Y, Bunker C. Left ventricular hypertrophy: a common finding in an adult African population in Tobago, West Indies-abstract. West Indian Med J. 1995;44(Suppl 3):20.

16. De Simone G, Devereux RB, Roman MJ, Alderman MH, Laragh $\mathrm{JH}$. Relation of obesity and gender to left ventricular hypertrophy in normotensive and hypertensive adults. Hypertension. 1994;23(5): 600-606.

17. Sato A, Tarnow L, Parving HH. Increased left ventricular mass in normotensive type 1 diabetic patients with diabetic nephropathy. Diabetes Care. 1998;21(9):1534-1539.

Vascular Health and Risk Management

\section{Publish your work in this journal}

Vascular Health and Risk Management is an international, peerreviewed journal of therapeutics and risk management, focusing on concise rapid reporting of clinical studies on the processes involved in the maintenance of vascular health; the monitoring, prevention and treatment of vascular disease and its sequelae; and the involvement of
18. Taskiran M, Rasmussen V, Rasmussen B, et al. Left ventricular dysfunction in normotensive Type 1 diabetic patients: the impact of autonomic neuropathy. Diabet Med. 2004;21(6):524-530.

19. Radice M, Alli C, Avanzini F, et al. Left ventricular structure and function in normotensive adolescents with a genetic predisposition to hypertension. Am Heart J. 1986;111(1):115-120.

20. Alli C, Avanzini F, DiTullio M, et al. Left ventricular diastolic function in normotensive adolescents with different genetic risk of hypertension. Clin Cardiol. 1990;13(2):115-118.

21. Chobanian AV, Bakris GL, Black HR, et al. Seventh Report of the Joint National Committee on Prevention, Detection, Evaluation, and Treatment of High Blood Pressure. Hypertension. 2003;42(6):1206-1252.

22. Perloff D, Grim C, Flack J et al. Human blood pressure determination by sphygmomanometry. Circulation. 1993;88(5):2460-2470.

23. WHO. Obesity and overweight. Global Strategy On Diet, Physical Activity And Health [serial on the Internet]. 2003 [cited 2009 June 12]. Available from: http://www.who.int/dietphysicalactivity/media/en/ gsfs_obesity.pdf. Accessed February 17, 2011.

24. WHO. MONICA Manual, Part IV: Event Registration. Section 4: ECG coding quality assurance methods [serial on the Internet]. 1990 [cited 2009 06/15]. Available from: http://www.ktl.fi/publications/monica/ manual/part4/iv-4.htm. Accessed February 17, 2011.

25. Sokolow M, Lyon TP. The ventricular complex in left ventricular hypertrophy as obtained by unipolar precordial and limb leads. 1949. Ann Noninvasive Electrocardiol. 2001;6(4):343-368.

26. Casale PN, Devereux RB, Kligfield P et al. Electrocardiographic detection of left ventricular hypertrophy: development and prospective validation of improved criteria. J Am Coll Cardiol. 1985;6:572-580.

27. Dijkstra RF, van Schayck CP, Bakx JC et al. Left ventricular hypertrophy; differences in the diagnostic and prognostic value of electrocardiography and echocardiography. Nederlands Tijdschrift Voor Geneeskunde. 1997;141(41):1969-1972.

28. Lang RM, Bierig M, Devereux RB, et al. Recommendations for chamber quantification: a report from the American Society of Echocardiography's Guidelines and Standards Committee and the Chamber Quantification Writing Group, developed in conjunction with the European Association of Echocardiography, a branch of the European Society of Cardiology. J Am Soc Echocardiogr. 2005;18(12):1440-1463.

29. The World Health Organization MONICA Project (monitoring trends and determinants in cardiovascular disease): a major international collaboration. WHO MONICA Project Principal Investigators. J Clin Epidemiol. 1988;41(2):105-114.

30. Devereux RB, Reichek N. Echocardiographic determination of left ventricular mass in man. Anatomic validation of the method. Circulation. 1977;55(4):613-618.

31. Ruiz-Nodar JM, Puchades R, Jimicnez-Borreguero J, et al. Echocardiographic findings in an elderly population. Influence of arterial hypertension. The EPICARDIAN study. Rev Esp Cardiol. 2008; 61(8):881-883.

32. Sokolow M, Lyon TP. The ventricular complex in left ventricular hypertrophy as obtained by unipolar precordial and limb leads. Am Heart J. 1949;37:161-186.

33. Rodrigues SL, D’Angelo L, Pereira AC, Krieger JE, Mill JG. Revision of the Sokolow-Lyon-Rappaport and Cornell voltage criteria for left ventricular hypertrophy. Arq Bras Cardiol. 2008;90(1):46-53.

34. Brown D, Giles WH, Croft J. Left ventricular hypertrophy as a predictor of coranary heart disease mortality and the effect of hypertension. Am Heart J. 2000;140(6):848-856.

\section{Dovepress}

metabolic disorders, particularly diabetes. This journal is indexed on PubMed Central and MedLine. The manuscript management system is completely online and includes a very quick and fair peer-review system, which is all easy to use. Visit http://www.dovepress.com/ testimonials.php to read real quotes from published authors. 